\title{
Comunicação pública ou marketing político? Um estudo sobre o uso do rádio por duas prefeituras de Pernambuco
}

Ana Paula Costa de Lucena

\section{Introdução}

Este artigo analisa as práticas de comunicação implementadas pelas prefeituras do Recife e de Caruaru, detendo-se essencialmente nos esforços de comunicação para o cidadão por meio do rádio. O estudo permitiu observar se o ato de comunicar dessas administrações municipais está mais voltado para uma comunicação pública ou para o marketing político. Os conceitos são bastante distintos, pois que comunicação pública prima pelo diálogo e pelo acesso à informação de interesse público enquanto o marketing político é promoção do gestor público.

O pesquisador Francisco Gaudêncio Rego definiu marketing político como “(...) um esforço planejado para se cultivar a atenção, o interesse e a preferência de um mercado de eleitores, é o caminho seguro para o sucesso de quem deseja vencer na política" (Rego, 1985, p. 23). Portanto, trata-se de uma técnica mercadológica que atua no âmbito de interesses políticos, buscando entender as necessidades/desejos da sociedade quando esta idealiza candidatos e políticos 
"perfeitos". A partir dessa leitura, constroem-se estratégias de marketing voltadas a convencer o cidadão que a melhor escolha é o político/candidato X ou reafirmar/ promover que o mais indicado já está ocupando a cadeira.

A discussão sobre o tema comunicação no âmbito governamental tem tido avanços no Brasil. Após a ditadura militar até os dias atuais, esta tem sido uma luta de muitos atores da sociedade civil, inclusive cobrando às gestões municipal, estadual e federal a elaboração de políticas de comunicação, o que torna o debate sobre o tema bastante oportuno.

As principais fontes primárias de pesquisa partiram dos releases, sugestões de pauta, matérias, boletins com sonora, áudios de programa e sugestões de nota, que foram sistematizadas nos acervos das secretarias de Comunicação das prefeituras do Recife e de Caruaru. Serviram também como dados primários as entrevistas realizadas com coordenadores de jornalismo, apresentador e gerente de conteúdo das rádios comerciais, localizadas nos municípios estudados.

Durante o labor investigativo, observou-se que as prefeituras do Recife e de Caruaru estão distantes da prática da comunicação pública. Como resultado, destaca-se o pouco empenho das prefeituras em informar e dialogar assuntos de interesse público com o cidadão.

\section{Comunicação Pública, um con- ceito pouco conhecido}

O tema Comunicação Pública começou a ser discutido conceitualmente no Brasil na década de 1990, inspirado no pequeno livro La communication publique, do autor francês Pierre Zémor ${ }^{1}$. A obra foi descoberta pela professora Heloiza Matos, na França, em 1995, quando realizava pesquisa sobre comunicação política. $\mathrm{Na}$ época, estudiosos e pesquisadores já procuravam literatura brasileira a respeito, mas não encontravam. Foi a partir desse contexto que a Dra. Elizabeth Pazito Brandão teve a iniciativa de desenvolver uma tradução resumida da obra de Zémor. A tradução "[...] acabou por se tornar um marco decisivo na concepção de Comunicação Pública" (BRANDÃo, 2009, p. 14).

O conceito chegou ao Brasil num momento político bastante peculiar. $\mathrm{Na}$ época, discutia-se sobre a construção da cidadania; a sociedade civil nascia e, no mesmo período, vários profissionais da área de comunicação acreditavam que a interface entre o Estado e o cidadão não poderia ficar a cargo apenas da mídia, pois que não era portadora da verdade. O pensamento do intelectual Zémor começou a encontrar consonância com as discussões no Brasil, principalmente quando defende ideias de que todos os gestores públicos devem prestar contas à sociedade. Este direito é garantido ao povo francês, graças ao Artigo 15 da Declaração dos Direitos do Homem e do Cidadão de 1789, da Constituição: "A sociedade tem o direito de pedir contas a todo agente público pela sua administração.”No livro $L a$ Communication Publique, Zémor traz conteúdos baseados na sua experiência na França. Ele escreve que os propósitos da comunicação pública caminham junto com os objetivos da instituição pública e suas funções são:

a) informar (levar ao conhecimento, prestar conta e valorizar); b) de ouvir as demandas, as expectativas, as interrogações e o debate público; c) de contribuir para assegurar a relação social (sentimento de pertencer ao coletivo, 
tomada de consciência do cidadão enquanto ator); d) e de acompanhar as mudanças, tanto as comportamentais quanto as da organização social (ZÉMOR, 2003, p. 76).

O estudioso define comunicação pública como sendo uma "comunicação formal que diz respeito à troca e à partilha de informações de utilidade pública, assim como à manutenção do liame social cuja responsabilidade é incumbência das instituições públicas" (ZÉmor, 2003, p.77). Ao analisar esse conceito, discorda-se do quesito "responsabilidade que cabe às entidades públicas" porque a dinâmica da troca de informações deve ser um movimento de todos, principalmente do cidadão. Em se tratando de Brasil, não podemos esperar pelos órgãos públicos. A grande maioria não tem interesse em informar, ouvir e assegurar espaços de diálogo para que o cidadão exerça o seu papel de ator-participante e incorpore a cultura do controle social. Vale lembrar que a comunicação é de domínio público e, para tanto, Zémor espera que a prática da comunicação pública "contribua para alimentar o conhecimento cívico, facilitar a ação pública e garantir o debate público.”(ZÉmOr, 2003, p.77).

A comunicação pública surge como ponte para romper a falta de diálogo entre o funcionário público inacessível, mal informado, que não sabe ouvir ou não quer, e pessoas interessadas em participar de discussões sobre assuntos de interesse público. À medida que a população cobrar essa dinamização dialógica, os servidores serão obrigados, pelas circunstâncias, a se informar mais e serem atentos aos conteúdos procurados. "O diálogo é uma forma de avaliação do serviço público e de recolher ideias, propostas, medir o grau de satisfação, formas de melhorias etc." (ZÉmor, 2003, p. 89). Assim, segundo Zémor, a comunicação pública se esforça para:

a) tornar mais acessível o serviço público; b) facilitar os contatos com o usuário; c) redesenhar a arquitetura interna dos locais a fim de evitar filas ou contribuir para que elas sejam mais suportáveis; d) estimular formas de trocas mais pessoais e conviviais com os usu-

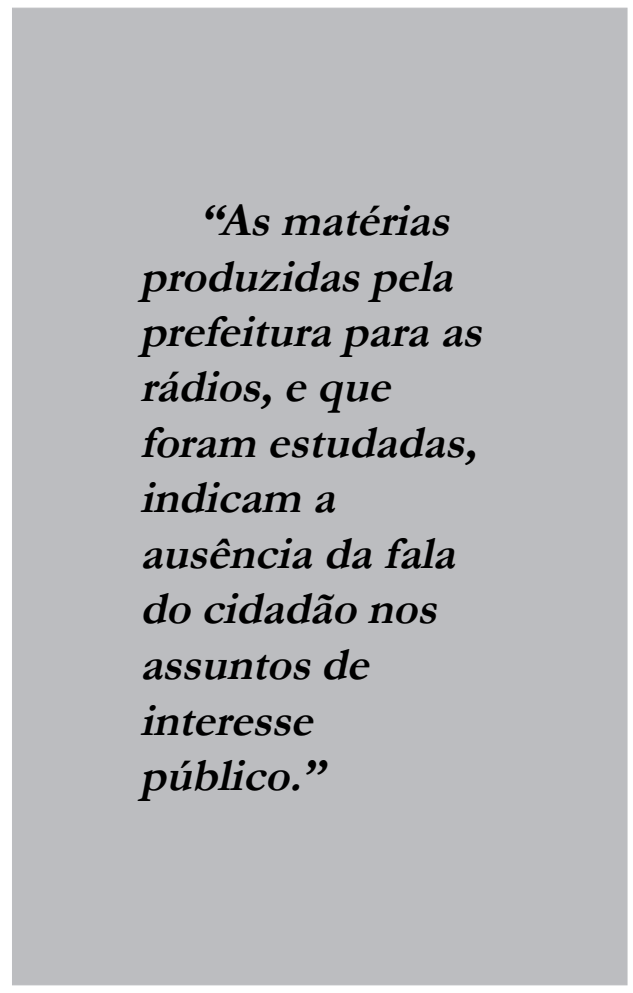

ários; e) adaptar os horários de funcionamento dos locais públicos para melhor atender o usuário; f) facilitar pequenos serviços necessários (posto bancário no local e em horário compatível, fotocopiadora etc.); g) serviço de teleatendimento (e não telemarketing), o que exige um tipo de treinamento diferente daquele que se faz para o mercado; h) atualização das informações nos 
postos, no teleatendimento, na internet (ZÉMOR, 2003, p. 88).

Em nosso país, existe uma tendência para identificar comunicação pública como a comunicação feita pelos órgãos do governo. Mas diante das várias visões interpretativas da expressão 'comunicação pública', "é possível encontrar um ponto comum de entendimento que é aquele que diz respeito a um processo comunicativo que se instaura entre o Estado, o governo e a sociedade com o objetivo de informar para a construção da cidadania" (BRANDÃo, 2009, p. 10). E acrescenta defendendo que o exercício da cidadania e a formação do espaço público dependem das condições de informação e comunicação.

A esfera pública é o palco principal para a prática da Comunicação Pública, desde que nela os atores - Estado, governo e sociedade - tenham as mesmas condições de falar e ouvir. Eis um exemplo de democracia que só será vivenciada a partir de mudanças culturais. Primeiro, o Estado deve garantir e fazer valer o direito do cidadão a ter acesso às informações. Segundo, a sociedade precisa entender que cabe a ela ser um cogestor das entidades públicas, procurando participar para compreender, entender e verificar se os recursos públicos estão sendo, por exemplo, empregados de acordo com os objetivos determinados. Grande parte da população não tem a cultura de cobrar accountability (prestação de contas), como também não vivencia a cidadania ao ponto de querer se envolver na discussão pelos assuntos de interesse coletivo. Quantos brasileiros incorporam esse comportamento à sua vida? ${ }^{2}$ Tal nível consciencial pertence a um número reduzido de pessoas, portanto o que prevalece são mordaças impostas por acreditar que não vale a pena falar ou buscar o que se deseja. Infelizmente, a maioria dos brasileiros não sabe que a comunicação é um direito humano (DECLARAÇÃo DOS DIreitos Humanos, 1948, Art. XIX) ${ }^{3}$. A terceira mudança depende de o governo compreender o papel da comunicação para uma gestão participativa e estabelecer políticas que garantam o acesso à informação e ao diálogo. São raros os gestores públicos e governantes que incluem na sua proposta de trabalho uma política de comunicação disposta a dialogar, com o cidadão, assuntos de interesse coletivo. Portanto, na prática o mais comum é vermos os esforços de comunicação serem trabalhados para promover a imagem do político e os seus feitos. Algumas dessas evidências podem ser percebidas a partir dos objetos estudados das prefeituras pesquisadas.

Brandão assevera que o conceito "comunicação pública” está em construção no Brasil e que existe um cuidado dos pesquisadores brasileiros em diferenciá-la da comunicação governamental (BRANDÃO, 2009, p. 14). Assim, do grupo de autores analisados para este estudo, Jorge Duarte é o único que traz um conceito que mais se identifica com Brandão, afirmando que

comunicação pública coloca a centralidade do processo de comunicação no cidadão, não apenas por meio da garantia do direito à informação e à expressão, mas também do diálogo, do respeito a suas características e necessidades, do estímulo à participação ativa, racional e co-responsável. Portanto, é um bem e um direito de natureza coletiva, envolvendo tudo o que diga respeito a aparato estatal, ações governamentais, partidos políticos, movimentos sociais, empresas públicas, terceiro setor e, até mesmo, em certas circunstâncias, às empresas privadas (DuARTE, 2009, p. 61). 


\section{Explicando a metodologia}

A pesquisa seguiu o método do estudo de caso, uma vez que a pergunta "Como as prefeituras do Recife e de Caruaru informam e dialogam assuntos de interesse público com o cidadão, através do rádio?" foi de cunho exploratório e questionou uma prática do cotidiano. Robert Yin afirma que "o estudo de caso é uma inquirição empírica que investiga um fenômeno contemporâneo dentro de um contexto da vida real, quando a fronteira entre o fenômeno e o contexto não é claramente evidente e onde múltiplas fontes de evidência são utilizadas" (YIN, 2001, p.32). Serviuse também do método análise de conteúdo porque se ocupou em examinar as mensagens. Segundo Laurence Bardin, a análise de conteúdo é "um conjunto de técnicas de análise das comunicações que utiliza procedimentos sistemáticos e objetivos de descrição do conteúdo das mensagens" (BARDIN, 2002, p.38).

Os materiais estudados foram produzidos pelas prefeituras ao longo dos anos 2009 e 2010. Objetos da Prefeitura do Recife: 123 boletins sonoros, 252 notícias para rádio, 183 sugestões de pauta e oito programetes de rádio. Prefeitura de Caruaru: 24 programetes de rádio, 23 notas e 15 sugestões de pauta. Além do arcabouço avaliado, foram entrevistados os responsáveis pela comunicação das entidades públicas estudadas e foi realizado um estudo teórico sobre Comunicação Pública, Comunicação de Interesse Público e Marketing Político.

\section{Indicadores de marketing polí- tico \\ Existe uma linha tênue entre o marketing político e a comunicação de}

interesse público, o que torna muitas vezes árdua a identificação de um e de outra. Por isso, faz-se pertinente a descrição dos quatro indicadores utilizados nesta pesquisa.

Os indicadores, desenvolvidos pela pesquisadora, nasceram após análises e investigações conceituais sobre Marketing Político, Comunicação Pública e Comunicação de Interesse Público. Assim, para melhor entender os relatos, a pesquisadora definiu quatro indicadores: Personalização, Autopromoção, Monofonia, e Fonte Única (Governo). É importante destacar que estes não existiam até serem criados para esta pesquisa.

A Personalização enfatiza a formação da identidade, pela repetição insistente do nome do político, slogan, mensagem, cor do partido (texto impresso ou virtual). A Autopromoção é o enaltecimento das ações governamentais com excessiva adjetivação nas informações, relatando apenas o lado bom, sem falar de problemas de gestão. $\mathrm{Na}$ Monofonia, a voz do cidadão está ausente, principalmente, quando é discordante. Para finalizar, Fonte Única (Governo) constitui-se quando a mensagem está centrada nas fontes de informação do governo e não inclui fontes alternativas.

As matérias, releases, sugestões de nota e programas das prefeituras de Recife e Caruaru foram analisados e classificados de acordo com os indicadores de marketing político. Vale ressaltar que alguns conteúdos se enquadraram em mais de um indicador.

\section{Prefeituras do Recife e de Caruaru, evidências de marketing político}

As prefeituras do Recife e de Caruaru investem de maneira relevante as suas atividades de comunicação no veículo rádio, principalmente a do Recife, por possuir uma 
diretoria de rádio e comunicação popular. Como os esforços de comunicação utilizados pelas prefeituras são extensos, a proposta foi analisar mais especificamente o rádio devido ao seu alcance, pois atinge todas as classes sociais e é um dos canais mais antigos do Brasil. Segundo os estudiosos Ari Luiz Cruz, Dacier Barros e Dirceu Tavares, o rádio "é o veículo de comunicação mais descentralizado do Estado e existem empresas localizadas em todas as macrorregiões. (...) Pernambuco apresenta extenso público consumidor do meio rádio. (...) $83 \%$ da população ouve rádio" (CRUZ; TAvares; Barros, 2006, p. 79-80). Adiante serão apresentados exemplos das prefeituras estudadas que foram analisados.

No mês de março de 2009, a matéria sonora Ordenamento da orla (1'56"), da repórter Renata Costa, segue o viés personalista: "O prefeito do Recife, em coletiva na tarde desta quarta-feira, explicou como está o processo de ordenamento do comércio na orla de Boa Viagem. João da Costa disse que nas negociações com representantes dos ambulantes houve acordo em vários pontos, principalmente quanto ao que está definido no decreto que regulamenta o comércio na orla. (...) João da Costa falou ainda da importância desse ordenamento para um dos principais cartões postais do Recife". A identidade do gestor municipal é reforçada pela repetição do seu nome e porque entre as falas da jornalista o prefeito faz duas intervenções.

Mais 122 famílias foram beneficiadas pelos programas habitacionais (1'24"), em 30 de julho de 2009. Tiago Salles: "Mais 122 famílias de baixa renda foram beneficiadas pelos programas habitacionais da Prefeitura do Recife. Nesta quinta, o prefeito João da Costa entregou os conjuntos habitacionais Várzea II, no bairro da Várzea, e Aritana, na Imbiribeira. O Várzea II atende a famílias que estavam no auxílio moradia e que vieram das comunidades Padre Jordano, em Boa Viagem, e da própria Várzea. Já Aritana recebe famílias da ZEIS Aritana, nas proximidades da Avenida Antônio Falcão. O prefeito João da Costa fala da alegria de poder realizar o sonho da casa própria para estas pessoas". Prefeito: "Isso aqui é o objeto do nosso trabalho, né? A gratificação de sempre que a gente pode fazer algo pela cidade, pelas pessoas é... a gente se sente recompensado pela nossa luta, pelo nosso trabalho, por enfrentar dificuldades. Então, é um momento que a gente realiza os objetivos de seu governo, de ter um projeto político, de poder mudar de forma objetiva, concreta a condição de vida de muita gente, né? Então, dentro das nossas limitações que é ser prefeito de uma cidade pobre como o Recife, poder articular recursos, realizar projetos que mudem a vida das pessoas nos deixa muito feliz, tão felizes quanto eles que vão receber a casa, né?”. Repórter: “Outros noves conjuntos habitacionais já estão em construção pela Prefeitura do Recife. Com notícias do Recife, Tiago Salles".

Nesta matéria, observa-se o esforço para associar o nome do prefeito ao grande feito que é "realizar o sonho da casa própria”. Esse entendimento é reforçado tanto nas palavras do repórter quanto nas do próprio gestor. Portanto, dois aspectos denotam a personificação. O primeiro é a repetição do nome do prefeito e o segundo está evidenciado na mensagem "o prefeito que dá casas aos pobres". Além disso, nota-se a autopromoção devido à reportagem estar mais interessada em mostrar "veja bem o que o prefeito João da Costa está dando aos pobres", do que informar ao cidadão quais são as políticas de habitação do município e seus projetos para os próximos três anos de mandato. 
Aniversário Lei Maria da Penha (1'39'), em 5 de agosto de 2009. Repórter Renata Costa: "Nesta quinta a Lei Maria da Penha completa três anos. Depois que foi sancionada pelo presidente Lula, a Lei Maria da Penha veio para coibir a violência contra a mulher. Juliana César, coordenadora da Mulher, fala o que mudou no Recife após a aplicação da lei". Coordenadora: "A mudança no Recife está inserida dentro de um contexto nacional que a Lei Maria da Penha trouxe além do debate na sociedade onde ela deveria ser vista como algo inaceitável, não seria um trabalho privado. Não é uma coisa particular entre as pessoas, mas é algo que o Estado, o poder público, tem que interferir. Criação de uma vara específica para tratar da violência contra a mulher fica aqui no Recife, isso fez com que o primeiro esforço Maria da Penha, que é um espaço exclusivo para tratar dessa temática no Poder Judiciário, fosse criado. Então alguns órgãos foram criados ou então foram redirecionados para atender exclusivamente este tema". Repórter: "Juliana Cesar também explica sobre os mecanismos utilizados pela prefeitura para as mulheres em situação de violência". Coordenadora: "A Prefeitura do Recife indicou que deveriam ser criados esses serviços de atendimento às mulheres em situação de violência. É um centro de referência com intervenções de várias espécies, que a casa abrigo sempre viva em que a situação de violência está tanta que a mulher corre o risco iminente de morte. Ela vai para esta casa pela Copefil e também o Disque Orientação 08002810100”. Repórter: "Outras atividades exercidas pela Prefeitura do Recife no combate à violência contra as mulheres é o bloco Nem Com Uma Flor, que desfila na semana précarnavalesca, e a caminhada de combate à violência contra a mulher, que acontece no dia 25 de novembro. Com notícias do Recife, Renata Costa".

O debate sobre a violência contra a mulher é uma falácia permeada por dúvidas, medos e questionamentos. Vale destacar que a mulher, como público principal do tema tratado, não foi ouvida. Onde está o seu ponto de vista? O que se observa é a divulgação de algumas ações para combater a violência, porém não se sabe a opinião

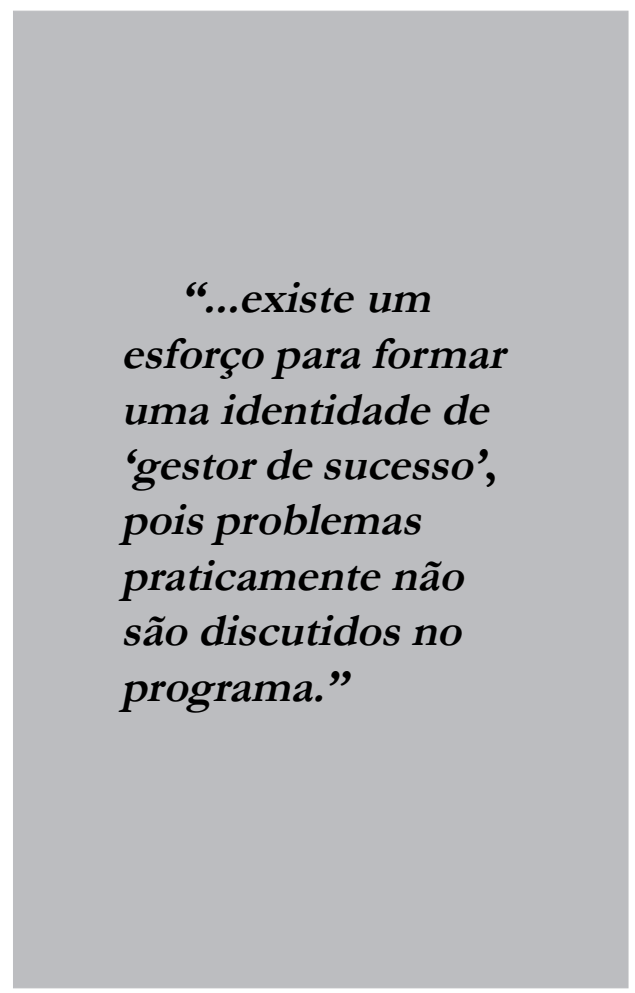

das mulheres e movimentos sobre a efetividade dessas atividades e propostas.

A formatação das matérias sonoras segue o roteiro de falas intercaladas entre o repórter e o gestor responsável pelo assunto em pauta. É importante chamar a atenção para a finalização dos áudios, que não informa o nome de contato para tirar dúvidas, tampouco o telefone do setor. 
Além do mais, não instrui o cidadão sobre como e onde obter mais informações ou até como participar para apoiar o projeto. $O$ recifense tem o direito de saber mais das ações. Onde procurar?

As matérias produzidas pela prefeitura para as rádios, e que foram estudadas, indicam a ausência da fala do cidadão nos assuntos de interesse público. Como foi observada, a monofonia é uma realidade na prática de comunicação da Prefeitura do Recife, porque mostra somente a expressão de um único ponto de vista sobre temas de ordem comum. Outra questão relevante é que, até onde foi possível pesquisar, não se ouviu ou leu um recifense discordando sobre pautas públicas.
Em Caruaru, a prefeitura tem o programa Bom Dia, Prefeito, veiculado nas rádios do município desde dezembro de 2009, às 7 horas. A Prefeitura de Caruaru compra espaços para transmitir o programa três vezes na semana (segundas, quartas e sextas-feiras) e as rádios recebem o programa somente em áudio, dessa forma, pronto para ser difundido. O viés do texto é informacional, sendo pautado o que é de interesse para a atual gestão e com evidentes promoções políticas. Mediante esta percepção, denota a falta de compromisso em ensinar à população como utilizar os serviços oferecidos pela prefeitura. Segue a descrição e análise de um desses programas, exibido em 30 de dezembro de 2009.

\section{Quadro 1: Abertura do programa Bom Dia, Prefeito.}

\begin{tabular}{|ll|}
\hline Locutor/Fonte & Discurso \\
\hline Locução 1 - voz única & "Bom dia, Prefeito!" \\
\hline Locução 2 - voz única & "Bom dia, Prefeito!" \\
\hline Locução 3 - voz única & "Bom dia, Prefeito!" \\
\hline Locução 4 - voz única & "Bom dia, Prefeito!” \\
\hline Locução 5 - várias vozes & "Bom dia, Prefeito!” \\
\hline Locução 6 - voz única & "O programa Bom Dia, Prefeito é a Prefeitura prestando \\
& contas ao povo". \\
\hline
\end{tabular}

Fonte: Secretaria de Comunicação de Caruaru, 2009.

Quadro 2 - Programa Bom Dia, Prefeito, quarta feira, 30 de dezembro de 2009 (4'56")

\begin{tabular}{|ll|}
\hline Locutor/Fonte & Discurso \\
\hline Apresentador Silvio & $\begin{array}{l}\text { "Hoje, quarta feira, dia } 30 \text { de dezembro, é o penúltimo dia de } 2009 . \\
\text { Bom dia a todos. Bom dia, prefeito." }\end{array}$ \\
\hline Prefeito José Queiroz & $\begin{array}{l}\text { "Bom dia, Silvio. Bom dia, meus amigos da cidade, da zona rural. } \\
\text { Bom dia, minhas queridas crianças de Caruaru." }\end{array}$ \\
\hline Apresentador Silvio & $\begin{array}{l}\text { "Prefeito, tivemos um resgate dos festejos natalinos. O ano termina } \\
\text { amanhã, tá confirmado o nosso réveillon?" }\end{array}$ \\
\hline
\end{tabular}


Quadro 2 - Programa Bom Dia, Prefeito, quarta feira, 30 de dezembro de 2009 (4'56")(continuação)

\begin{tabular}{|c|c|}
\hline Locutor/Fonte & Discurso \\
\hline Prefeito José Queiroz & $\begin{array}{l}\text { "Evidente, Silvio, esse ano a gente teve um natal cheio de luzes, } \\
\text { cores. Está tendo uma movimentação muito grande, a cidade está } \\
\text { participando, a zona rural também. E o fechamento do Natal é o } \\
\text { réveillon, que é uma coisa universal, no mundo inteiro. E aí a gente } \\
\text { vai ter também o réveillon de Caruaru, vai ser vivido na frente da } \\
\text { Igreja da Conceição, como muitos caruaruenses se acostumaram a } \\
\text { participar. Lógico, mas não vai ficar só lá. Nós vamos ter nos restau- } \\
\text { rantes, nas casas de residência (sic), nos bares, também na cidade } \\
\text { natalina lá no largo da estação ou este réveillon na Igreja da Concei- } \\
\text { ção, em frente à Igreja da Conceição, no marco zero. Então, vai ser } \\
\text { um réveillon de muita alegria, de muitos fogos, de muitas cores. Um } \\
\text { réveillon para ficar na memória e na história de Caruaru." }\end{array}$ \\
\hline Apresentador Silvio & $\begin{array}{l}\text { "Além do réveillon, Prefeito, quais são as outras boas notícias que o } \\
\text { senhor tem pra Caruaru?" }\end{array}$ \\
\hline Prefeito José Queiroz & $\begin{array}{l}\text { "Olha, Silvio, eu diria que nós estamos vivendo um término de ano, } \\
\text { não é? - porque, lógico, amanhã é o último dia do ano - comemo- } \\
\text { rando as boas notícias: foi a assinatura junto à Caixa Econômica } \\
\text { Federal da verba de mais de dezoito milhões, quase dezenove mi- } \\
\text { lhões de reais conseguida pelo deputado Volney Queiroz para o } \\
\text { banho asfáltico de Caruaru, mas também outra emenda do deputado } \\
\text { Volney Queiroz com trezentos mil reais para o Parque das Rendeiras. } \\
\text { Eu já estou com psicose de parque, eu tenho certeza que vai ser } \\
\text { algo diferenciado na minha administração para a vida dos caruaru- } \\
\text { enses e esta verba de Volney Queiroz vai servir pra gente implantar } \\
\text { o mais depressa possível o Parque das Rendeiras, o Parque da Cohab } \\
\text { III que vai ser um negócio fantástico também, a exemplo do que é o } \\
\text { primeiro Parque Severino Montenegro. Eu diria, então, que estamos } \\
\text { terminando o ano com o balanço mais que positivo." }\end{array}$ \\
\hline Apresentador Silvio & $\begin{array}{l}\text { "Esse realmente foi um ano de grandes conquistas e para os funcio- } \\
\text { nários municipais, em especial, foi um ano pra ficar na história. Pre- } \\
\text { feito, explique pra gente o porquê dessa satisfação dos funcionários." }\end{array}$ \\
\hline Prefeito José Queiroz & $\begin{array}{l}\text { "Olha, Silvio, hoje é o último dia da folha de pagamento, né? Hoje é } \\
\text { o último dia de pagamento do servidor municipal. Ele sabe mais do } \\
\text { que ninguém, ele tem manifestado esta alegria porque nós pagamos } \\
\text { rigorosamente todos os meses, apesar da crise, ao nosso servidor. } \\
\text { Nós estabelecemos o piso nacional do salário com efeito retroativo } \\
\text { a janeiro e isso tem dado uma satisfação muito grande aos servidores. } \\
\text { Nós fizemos uns reajustes dos médicos e estamos pagando nor- } \\
\text { malmente esses reajustes. As aposentadorias foram retomadas e o } \\
\text { pagamento é feito pelo Caruaru Prev, normalmente. A progressão } \\
\text { funcional foi respeitada e aquilo que muitos, muitos ainda não acre- } \\
\text { ditavam, aconteceu: o pagamento do décimo terceiro salário a todos } \\
\text { indistintamente, inclusive os contratados. E o mais importante, né? }\end{array}$ \\
\hline
\end{tabular}


Quadro 2 - Programa Bom Dia, Prefeito, quarta feira, 30 de dezembro de 2009 (4'56")(continuação)

\begin{tabular}{|ll|}
\hline $\begin{array}{l}\text { Prefeito José Queiroz } \\
\text { (continuação) }\end{array}$ & É que os servidores contratados, eles eram demitidos. Não tem que \\
& falar só no pagamento do décimo terceiro, eles eram demitidos. Hoje \\
& não, eles permanecem, sabem que vão continuar em janeiro e vão \\
& ter naturalmente... ah... esse respeito que nós vamos, devemos ter a \\
& ele. Essa é a linha humana do nosso governo, que vai prosseguir \\
& durante os quatro anos." \\
\hline Apresentador Silvio & "É chegado o final de mais um Bom Dia, Prefeito, mas antes da gente \\
& encerrar, em nome dos nossos ouvintes, em nome da nossa produ- \\
& ção, os nossos parabéns pelo seu aniversário, que é hoje. Muita saúde \\
& e muita felicidade, prefeito José Queiroz". \\
\hline Prefeito José Queiroz & "E eu estou imensamente feliz, completando idade hoje, porque \\
& $\begin{array}{l}\text { estou ficando mais experiente. Vocês não queiram saber como a } \\
\text { experiência me valeu para este primeiro ano de dificuldades. Como }\end{array}$ \\
& a experiência me valeu para superar com a minha equipe de trabalho, \\
& com quem eu divido todas as vitórias desse ano. Então, eu quero \\
& agradecer já as manifestações logo cedo recebidas pelo meu aniver- \\
& sário. Bom dia! Graças a Deus estamos comemorando esse momento, \\
& que é um momento de alegria meu e dos caruaruenses. Até a próxima \\
& sexta-feira já com o ano novo, se Deus quiser." \\
\hline
\end{tabular}

Fonte: Secretaria de Comunicação de Caruaru, 2009

\section{Quadro 3 - Encerramento do Programa Bom Dia, Prefeito}

\begin{tabular}{|ll|}
\hline Locutor/Fonte & Discurso \\
\hline $\begin{array}{l}\text { Locução } 1 \text { - voz única } \\
\text { tas ao povo". }\end{array}$ & "O programa Bom Dia, Prefeito é a Prefeitura prestando con- \\
\hline Locução 1 - voz única & "Bom dia, prefeito!” \\
\hline Locução 2 - voz única & "Bom dia, prefeito!” \\
\hline Locução 3 - voz única & "Bom dia, prefeito!” \\
\hline Locução 4 - voz única & "Bom dia, prefeito!” \\
\hline Locução 5 - várias vozes & "Bom dia, prefeito!” \\
\hline
\end{tabular}

Fonte: Secretaria de Comunicação de Caruaru (2009) 
Todos os programas começam e encerram com a mesma vinheta, mudando somente a ordem de entrada do slogan. Ou seja, na abertura do programa o slogan é pronunciado no final, enquanto que no término o slogan vem primeiro.

No programa do dia 30 de dezembro de 2009 constatam-se indícios de marketing político. A personalização é notada devido à presença de slogan; o nome do gestor ou simplesmente a palavra "prefeito" são repetidos várias vezes pelo apresentador; existe um esforço para formar uma identidade de "gestor de sucesso", pois problemas praticamente não são discutidos no programa.

O quesito autopromoção - o prefeito discursa entoado por adjetivação e se colocando como o grande marco da gestão de Caruaru - foi a principal impressão ao ler o texto do programa. O prefeito José Queiroz faz um balanço do seu governo abordando apenas o lado positivo, sendo reforçado por frases do tipo “(...) eu diria, então, que estamos terminando o ano com o balanço mais que positivo (...)"; “(...) essa é a linha humana do nosso governo, que vai prosseguir durante os quatro anos (...)" e "(...) eu tenho certeza que vai ser algo diferenciado na minha administração para a vida dos caruaruenses (...)". O apresentador endossa o enaltecimento quando fala: “(...) esse realmente foi um ano de grandes conquistas e para os funcionários municipais, em especial, foi um ano pra ficar na história (...)". Além de enaltecer-se, enaltece também as ações do deputado Volney Queiroz, repetindo seu nome três vezes.

Ao ouvir essa locução, notou-se a ausência de outros atores que podiam ter sido escutados. Por exemplo, o cidadão caruaruense, para expressar seu ponto de vista sobre os parques e a festa de réveillon; os servidores públicos, para falar se estão realmente satisfeitos com o reajuste salarial ou não. E os médicos, que também tiveram seus vencimentos reajustados. Percebe-se, assim, o mínimo de esforço em estabelecer uma dinâmica de comunicação (diálogo) que contemple vários olhares sobre o mesmo assunto. Esta seria uma comunicação genuinamente democrática e participativa. Sem contar que a produção do programa não

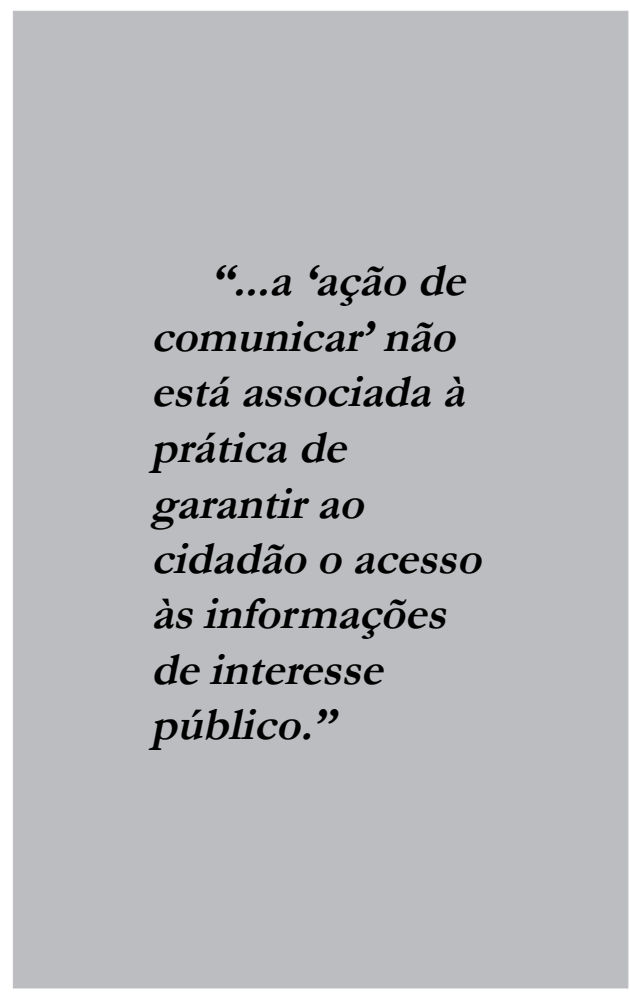

buscou outras fontes de informação. Poderiam ter falado presidentes de associações de moradores próximas aos parques, representantes do Caruaru Prev e o presidente do Conselho de Médicos de Caruaru.

No programa de 15 de janeiro de 2010, o apresentador segue com a estratégia de repetir várias vezes o nome do prefeito, além do slogan, marca registrada para formar a identidade política do gestor municipal. 
Quadro 4 - Programa Bom Dia, Prefeito, sexta-feira, 15 de janeiro de 2010 (5’09’)

\begin{tabular}{|c|c|}
\hline Locutor/Fonte & Discurso \\
\hline Apresentador: Silvio & $\begin{array}{l}\text { "Hoje é sexta feira, dia 15. Já estamos no meio do mês. Bom dia, } \\
\text { prefeito José Queiroz". }\end{array}$ \\
\hline Prefeito: José Queiroz & $\begin{array}{l}\text { "Bom dia, Silvio, bom dia amigos e amigas da cidade, da zona rural. } \\
\text { Minhas queridas crianças de Caruaru". }\end{array}$ \\
\hline Apresentador: Silvio & $\begin{array}{l}\text { "O que o prefeito destacaria de ações do governo que estão em } \\
\text { andamento agora em janeiro, prefeito José Queiroz". }\end{array}$ \\
\hline $\begin{array}{l}\text { Prefeito: José Queiroz } \\
\text { (continuação) }\end{array}$ & $\begin{array}{l}\text { "Olha, Silvio, é tanta coisa, mas tanta coisa boa. Por exemplo, estamos } \\
\text { terminando as creches do Cedro e do Rafael. A Academia das Cida- } \\
\text { es, no meu querido bairro do Salgado, em parceria com o governo } \\
\text { Eduardo Campos, está dentro do cronograma e logo estará disponível } \\
\text { para o lazer da população lá do São João da Escócia. As atividades } \\
\text { esportivas de orientação à saúde, de jogos e lazer, serão conduzidas } \\
\text { por professores de educação física e especialistas da Secretaria de } \\
\text { Saúde. A Academia do Povo, na Nova Caruaru, está em construção } \\
\text { e terá função idêntica à Academia das Cidades, a diferença é que ela } \\
\text { estará inserida num projeto comunitário e de paisagismo que inclui } \\
\text { a igreja do bairro e áreas mais amplas para o divertimento das crian- } \\
\text { ças. A Praça do Rosário... Ah! a Praça do Rosário... continua, avança } \\
\text { firme, assim como prossegue a construção da Ponte de Riachão em } \\
\text { Dianópolis e todo complexo urbano, porque não é só a ponte. Espe- } \\
\text { rem e vocês vão ver. A perspectiva de entregar essas duas obras } \\
\text { simbólicas dos novos tempos de Caruaru é o mês de maio, se Deus } \\
\text { quiser, se nenhum atropelo houver, tenho certeza que essas duas } \\
\text { obras serão entregues no ar, na semana do aniversário de Caruaru”. }\end{array}$ \\
\hline Apresentador: Silvio & "Prefeito, e na área da saúde, quais são as ações?". \\
\hline Prefeito: José Queiroz & $\begin{array}{l}\text { "Olha, tão importante quanto qualquer obra física, assim como rea- } \\
\text { lizamos na Policlínica, realizamos na Policlínica do Salgado, está sendo } \\
\text { a informatização de todo o sistema de saúde pública sob o comando } \\
\text { do governo municipal. Ao integrar por via informática todos os } \\
\text { hospitais e unidades de atendimento, a rede fica ao alcance de um } \\
\text { comando para os usuários. Ficam facilitadas as marcações de con- } \\
\text { sultas e o acompanhamento dos pacientes com os respectivos exames } \\
\text { e prontuário de atendimento. Caruaru, finalmente, assume um lugar } \\
\text { de destaque na modernização do seu serviço municipal de saúde. } \\
\text { Ao mesmo tempo continuam as reformas nas unidades de atendi- } \\
\text { mento, até que todas fiquem no padrão da Policlínica do Salgado, } \\
\text { com ar condicionado, TV de plasma, assentos modernos, no formato } \\
\text { longarina, e instalações condignas para médicos e pacientes. Mas, } \\
\text { não esqueçam, tem de ser unidade de qualidade e bom atendimento, } \\
\text { com médicos trabalhando e pacientes satisfeitos." }\end{array}$ \\
\hline Apresentador: Silvio & "Prefeito, há novidades no setor de infraestrutura?" \\
\hline Prefeito: José Queiroz & $\begin{array}{l}\text { "Com as licitações em curso, está cada vez mais próximo o dia do } \\
\text { início do cabeamento asfáltico da cidade, bem como dos }\end{array}$ \\
\hline
\end{tabular}


Quadro 4 - Programa Bom Dia, Prefeito, sexta-feira, 15 de janeiro de 2010 (5’09’) (continuação)

\begin{tabular}{|ll|}
\hline Locutor/Fonte & Discurso \\
\hline $\begin{array}{l}\text { Prefeito: José Queiroz } \\
\text { (continuação) }\end{array}$ & investimentos em calçamento em mais uma dezena de bairros. Até o \\
& mês do aniversário da cidade, Caruaru terá uma nova fisionomia \\
& urbanística; temos certeza, com base na nossa experiência de admi- \\
& nistrador. Bem, assim a questão do trânsito, a Destra, está cumprindo \\
& sem atropelos os seus cronogramas de concursos e contratações. Se \\
& tudo continuar no ritmo atual, em abril já teremos guardas nas ruas, \\
& lotações nos terminais adequados, inclusive com semáforos novos - \\
& dotados do sistema LED -, que dá mais visibilidade ao motorista, \\
& economiza energia e tem maior durabilidade. Não quero nem pedir \\
& paciência à população, quero anunciar que em cento e vinte dias \\
& Caruaru mandará, definitivamente, para o passado o caos que her- \\
& damos das administrações anteriores. Mesmo reconhecendo o incô- \\
& modo que ainda nos atinge a todos, temos a perspectiva otimista de \\
& que superaremos o desafio de dar à capital do agreste um trânsito à \\
& altura do papel da capital regional, que desempenhamos com muito \\
& orgulho. É só aguardar. O novo tempo está se vestindo e todos \\
& vamos nos beneficiar. Mas eu quero lembrar também, Silvio, que \\
& nós estamos, estaremos começando a urbanização da via principal \\
& do distrito industrial e também o acesso ao Alto do Moura para dar \\
& início ao grande projeto de revitalização e de transformação do Alto \\
& do Moura, num point internacional, num sítio de cultura. Tem muito \\
& mais, mas depois a gente conversa." \\
\hline "Tá bom. Prefeito, assim a gente termina mais uma edição do Programa \\
Bom Dia, Prefeito. Bom dia a todos, bom dia, prefeito José Queiroz". \\
\hline Prefeito: José Queiroz "Bom dia, Silvio, bom dia, amigos e até a próxima segunda-feira, se \\
Deus quiser". \\
\hline Apresentador: Silvio \\
\hline
\end{tabular}

Fonte: Secretaria de Comunicação de Caruaru, 2010.

Ouvindo este e os demais programas, tem-se a impressão de um tom entusiasmado - quando falam das obras e dos feitos. Ao ser indagado pelo apresentador sobre as ações do governo, em andamento no mês de janeiro de 2010, o prefeito apenas as descreve sem maiores informações. Além de investir verticalmente na autopromoção, é próprio do gestor exaltar e falar dos projetos com muitos adjetivos, exemplos: “(...) grande projeto de revitalização e de transformação do Alto do Moura, num point internacional, num sítio de cultura (...)"; "A
Academia das Cidades, no meu querido bairro do Salgado (...)".

Uma das informações que mereceram destaque neste Bom dia, Prefeito foi a modernização do serviço municipal de saúde, ao ser divulgado que a Policlínica do Salgado está sendo informatizada. Porém, em momento algum o programa se preocupou em informar ao cidadão um telefone de contato e como proceder para marcar consultas e exames. De que adianta modernização no serviço de saúde, se o caruaruense não souber como e onde utilizar o serviço? 


\section{Considerações finais}

A partir do estudo, observou-se que as prefeituras do Recife e de Caruaru destinam grande parte dos seus esforços de comunicação com o cidadão por meio do rádio para atender às estratégias de marketing político. Nesses esforços, a "ação de comunicar" não está associada à prática de garantir ao cidadão o acesso às informações de interesse público, tampouco promover espaços de diálogo, e a realidade configurase um grande hiato entre prefeitura e munícipe. Desse modo, as análises levamnos a concluir que tal prática de comunicação exercida por essas prefeituras está direcionada à autopromoção dos seus gestores.

Com base nos materiais estudados, e na utilização dos indicadores inéditos de diferenciação criados, constatamos que a Prefeitura de Caruaru direciona fortemente a comunicação para exaltar - com expressivo exagero - a personalidade do "prefeito eficiente e eficaz". A do Recife desenvolve as estratégias de marketing político de maneira sutil, porém não menos reveladora, direcionando a comunicação para fortalecer a imagem do "gestor de sucesso".

Assim, depois dessas observações, o que ainda há para dizer sobre a atuação das prefeituras nas rádios? Talvez caiba uma resposta direta: a comunicação praticada por essas entidades públicas está instrumentalizada no marketing político e distante da comunicação pública, que prima pelo diálogo entre governo, Estado e sociedade.

Em termos mais amplos de uma gestão pública, tal situação pode favorecer a permanência de uma sociedade desinformada, alheia aos assuntos de interesse público e desacreditada na possibilidade de dialogar com as prefeituras. Mesmo com a realização desses programas e do uso das rádios como ponte entre esses atores sociais, a comunicação governamental que se pauta pela ótica do marketing político não é sem custos para os cidadãos, pois reforça a postura de espera pelo acesso à informação nas administrações municipais, que dificulta a realização de uma verdadeira comunicação pública.

(Artigo recebido em setembro de 2011. Versão final em janeiro de 2012).

\section{Notas}

${ }^{1}$ Presidente da Federação Europeia de Comunicação Pública e fundador presidente da Associação Francesa de Comunicação Pública.

${ }^{2}$ O Fórum Pernambuco de Comunicação (Fopecom) tem ministrado palestras, cursos e oficinas sobre os temas tratados nestas afirmações e, costumeiramente, a grande maioria dos participantes desconhece o tema e a sua prática.

${ }^{3}$ Artigo XIX - Todo ser humano tem direito à liberdade de opinião e expressão; este direito inclui a liberdade de, sem interferência, ter opiniões e de procurar, receber e transmitir informações e ideias por quaisquer meios e independentemente de fronteiras. 


\section{Referências bibliográficas}

Bardin, Laurence. Análise de conteúdo. Tradução Luís Antero Reto e Augusto Pinheiro. Lisboa: Edições 70, 2002.

Brandão, Elizabeth Pazito. Conceito de comunicação pública. In: Duarte, Jorge (Org.). Comunicaşão Pública: estado, mercado, sociedade e interesse público. São Paulo: Atlas, 2009. Cap. 1, p.1-33.

Usos e significados do conceito comunicação pública. In: ENCONTRO dos Núcleos de Pesquisa da Intercom, 6., São Paulo, 2006. Resumos... Disponível em: <www.rp-babia.com.br/biblioteca/intercom2006/resumos/R1037-1.pdf>. Acesso em: 20 jul. 2009.

Câmara Municipal de Caruaru. Lei Orgânica do Município de Caruaru. Promulgada 05 abr. 1990. Da Política de Saúde. Art. 128 e 129. Caruaru, 1990.

Cruz, Ari; TAvares, Dirceu; Barros, Dacier. Razão e comunicação: elementos de uma identidade nacional. Recife: Ed. Universitária da UFPE, 2006.

DuARTE, Jorge. Instrumentos de comunicação pública. In: DuARTe, Jorge (Org.). Comunicação pública: Estado, mercado, sociedade interesse público. São Paulo: Atlas, 2009.

LiRA, Rui. O trabalho da Secretaria de Comunicação na Prefeitura de Caruaru: entrevista [10 dez. 2009]. Entrevistadora: Ana Paula Costa de Lucena. Caruaru, PE.

Melo, Dulce. Diretoria de rádio e comunicação popular: entrevista [26 out. 2009]. Entrevistadora: Ana Paula Costa de Lucena. Recife, PE.

Organização das NaÇões Unidas (Onu). Declaração Universal dos Direitos Humanos. 1948. Disponível em: <http://www.gddc.pt/direitos-humanos/textosinternaiconais-dh/regionais.html>. Acesso em: 3 maio 2009.

Rego, Francisco Gaudêncio. Marketing político e governamental: um roteiro para campanhas políticas e estratégia de comunicação. São Paulo: Summus, 1985.

RecIFE. Lei Orgânica do Município de Recife. Promulgada em 04 abr. 1990. Câmara Municipal do Recife. Da administração pública municipal. Art. 64 e 67.

Disponível em: <http://www.camara.recife.pe.gov.br/leis/lei-organica-do-municipiodo-recife/leiorganicadorecifeatualizadaem20-1-08-2008.rar/view >. Acesso em: 17 dez. 2009.

YIN, Robert K. Estudo de caso: planejamento e métodos. 2. ed. Porto Alegre: Bookman, 2001.

Zémor, Pierre. Comunicação pública. In: Silva, Luiz Martins da (Org.). Algumas abordagens em comunicação pública. Brasília: Casa das Musas, 2003, p. 76-103. (Versão traduzida, resumida e comentada pela Profa. Dra. Elizabeth Brandão do livro ZÉMor, Pierre. La Communication publique. PUF, Col. Que sais-je? Paris, 1995).

Governo e Comunicação Pública, a Experiência Francesa. Palestra. Escola Nacional de Administração Pública (ENAP). Brasília, 2009. 


\section{Resumo - Resumen - Abstract}

Comunicação pública ou marketing político? Um estudo sobre o uso do rádio por duas prefeituras de Pernambuco

Ana Paula Costa de Lucena

O trabalho analisou as práticas de comunicação implementadas pelas prefeituras do Recife e de Caruaru, detendo-se essencialmente nos esforços de comunicação para o cidadão por meio do rádio. Permitiu observar se o ato de comunicar dessas administrações municipais está mais voltado para uma comunicação pública ou para o marketing político. Para isso, a pesquisadora criou indicadores de diferenciação inéditos entre os temas comunicação pública e marketing político. As principais fontes foram os releases, matérias, áudios de programa e sugestões de nota, dos acervos das secretarias de Comunicação das prefeituras do Recife e de Caruaru. Durante o período de análise, observou-se que as prefeituras estudadas estão distantes da prática da comunicação pública. Como resultado, destaca-se o pouco empenho das prefeituras em informar assuntos de interesse público e dialogar com o cidadão.

Palavras-chave: Comunicação Pública; Comunicação de Interesse Público; Marketing Político; Rádio; Cidadania.

\section{¿Comunicación pública o marketing político? Un estudio sobre el uso de la radio en} dos alcaldías de Pernambuco (Brasil)

Ana Paula Costa de Lucena

El trabajo analizó las prácticas de comunicación implementadas por las alcadías de Recife y de Caruaru, y se detuvo esencialmente en los esfuerzos de comunicación para el ciudadano por medio de la radio. Lo que permitió observar si el acto comunicacional de esas administraciones municipales está más volcado hacia la comunicación pública o el marketing político. Por ello, la investigadora creó indicadores inéditos de diferenciación entre los temas de comunicación pública y marketing político. Como fuentes principales se utilizaron los releases, materias, audios de programa y sugerencias de nota de los acervos de las secretarias de Comunicación de dichas alcaldías. Durante el período de análisis, se observó que las alcadías estudiadas estaban lejos de la práctica de comunicación pública. Como resultado, se destacó el poco empeño por parte de las alcadías en informar acerca de asuntos de interés público y en dialogar con los ciudadanos.

Palabras clave: Comunicación Pública; Comunicación en el Interés Público; Marketing Político; Radio; Ciudadanía.

\section{Public Communication or Political Marketing? A case study of two local government radio stations in the state of Pernambuco (Brazil)}

Ana Paula Costa de Lucena

This paper analyzes the communication practices implemented by municipal governments from the cities of Recife and Caruaru, essentially centered on communication efforts aimed at citizens through the radio medium. This allowed the observation of whether these municipal governments' acts of communicating point to public communication or political marketing. In order to achieve this, the researcher has created new indicators to differ public communication from political marketing. The main sources used were press releases, articles, audio programs and news flashes suggestions from the archives of the Communications secretariats from the municipal administration offices of both cities: Recife and Caruaru. During the period analyzed, it was observed that the studied municipal governments are far from the practice of public 
communication. As a result, the little effort put by the cities administrations into informing matters of public interest and creating space for dialogue with citizens is highlighted.

Keywords: Public Communication; Communication of Public Interest; Political Marketing; Radio; Citizenship.

Ana Paula Costa de Lucena

Mestre em Gestão Pública para o Desenvolvimento do Nordeste pela Universidade Federal de Pernambuco (UFPE), gestora lotada na Secretaria de Transportes do Estado de Pernambuco, professora da Faculdade SENAC-PE, professora executora do curso de Administração Pública (modalidade a distância) pela Universidade Federal Rural de Pernambuco (UFRPE) e membro do Fórum Pernambucano de Comunicação (FOPECOM). Contato: anapaula.lucena@yahoo.com.br 